\title{
Flowering under short days: juvenile period and inductive phase estimates in soybean genotypes
}

\author{
Arlindo Harada',*, Leandro Simões Azeredo Gonçalves ${ }^{2}$, Romeu Afonso de Souza Kiihl ${ }^{3}$ and \\ Deonisio Destro 4
}

${ }^{1}$ Fundação de Apoio à Pesquisa Agropecuária de Mato Grosso, Cambe, PR, Brazil. ${ }^{2}$ Departamento de Agronomia, Universidade Estadual de Londrina, PR, Brazil. *Co-corresponding author, E-mail: arlindoharada@tmg.agr.br ; deonisiodestro@yahoo.com

\begin{abstract}
The success in adapting Brazilian soybean cultivars to low latitude regions was attained thanks to the incorporation of the late flowering trait into the germplasm used by breeders. The objective of the present work was to establish a methodology to estimate the juvenile period and the inductive phase of soybean genotypes. A total of 11 cultivars representing the successful trajectory of the genetic progress of soybean breeding in Brazil were used. The experiments were done under greenhouse conditions in the city of Cambé, PR, Brazil. Seeds were germinated at 14 days intervals and, after emergence, the plants were subjected to continuous light for periods varying from 0 to 56 days. The number of days for flowering under the different light regimes and sowing times was evaluated. A decreasing exponential regression model was adjusted, through the differences between the maximum and minimum partial points of the function, in order to estimate the juvenile period. Results showed that, except for 'Viçoja', all the other cultivars fitted into the model. 'Paraná' had an almost linear behavior with the equilibrium point at the zero value. 'Paranagoiana' was the cultivar with the largest and most significant juvenile period while 'Viçoja' and 'ÚFV-1' showed the lowest juvenile period. The methodology developed appeared to be robust and was validated by the known behavior of such cultivars when sowed under short day conditions that occurs either in low latitudes or anticipated and delayed sowing seasons.
\end{abstract}

Key words: Glycine max, vegetal physiology, latitude, light.

\section{INTRODUTION}

Soybean (Glycine max (L.) Merrill) is originally from northeast China and ranks fourth in world grain production (261 million tons/ year), after corn (Zea mays L.) (814 million tons/ year), wheat (Triticum aestivum L.) (647 million tons/ year), and rice (Oryza sativa L.) (441 million tons/year). The US is the first largest world producer of this legume, producing 91 million tons, followed by Brazil and Argentina with 72 and 50 million ton, respectively (Destro et al. 2013).

In the US and Argentina, soybean is cultivated in regions with latitudes similar to the center of origin of the species. In Brazil, the cultivation occurs in tropical and subtropical climates and even in the equatorial region. In this sense, the development of cultivars adapted to low latitude regions and little sensitive to sowing dates can be obtained by adopting a long juvenile period (LJP) traits (Kiihl and Almeida 2001).

Soybeans are classified as short days (or long nights) plants because they flower when days are shorter than a certain critical period (Hicks 1978). Each cultivar has its specific critical period thus it is essential to determine its optimal sowing period and adaptation area. Soybean cultivars are generally adapted to narrow latitudinal bands and, despite the temperature's influence on their adaptation and its significant interaction with the photoperiodic response, the photoperiod is the predominant factor (Kiihl and Almeida 2001).

The identification of neutral or insensitive to photoperiod soybean genotypes did not bring a contribution to breeding programs for low latitudes. Therefore, another approach was to identify genotypes of late flowering under short-day conditions such as 'Santa Maria', PI 240664, PI 159925 and PI 274454 (Kiihl and
Garcia 1989).

The late flowering trait under short-day conditions is referred to as a long juvenile period. Thus, juvenility is the name given to the early stages of vegetative growth in which the plant is not induced to flower, even under inductive condition. The inheritance of a long juvenile period trait in soybean is controlled by the interaction between major genes with marked effects with smaller genes with less pronounced effects (Destro et al., 2001; Sinclair et al., 2005; Cober and Voldeng 2001a; Cober Voldeng 2001b; Cober et al. 2010; Cober 2011).

In developing soybean cultivars for low latitudes, a long juvenile period trait is not necessary; however, it is extremely convenient for a better adaptation to tropical regions. As the genetic control of the trait is simple, the genotype selection process for short-day conditions is facilitated. A long juvenile period trait makes cultivars insensitive to sowing dates, enables seeds production in the autumn/winter season and allows cultivation over wide ranges of adjustment.

Studies on the number of days to flowering traits should consider the two main stages that occur between seedling emergence and the opening of the first flower mentioned below: i) the juvenile period - stage between seedling emergence and initial detection of short days or long nights conditions during which plants become sensitive to changes in photoperiod thus moving to the inductive phase when sufficiently dark; and ii) the inductive phase - which covers the period between the start of the induction to flowering and the opening of the first flower. The beginning of the inductive phase occurs immediately after the plant's juvenile period.

Therefore, in short-day plants, the vegetative phase or the number of days to flowering comprises the sum of the juvenile 
period and the inductive phase. The soybean breeding programs conducted for the purpose of obtaining material to adapt to wide ranges of latitude can be effective in identifying and selecting genotypes with long juvenile period, anticipating the sowing of genotypes in one to two months at the normal time in the region, simulating short days. Under these conditions, genotypes with proper plant development that flowers about 40 to 60 days after emergence and matures between 110 and 140 days, with plant height between $0.70 \mathrm{~m}$ and $1.00 \mathrm{~m}$, are identified. These genotypes are selected and used to generate cultivars with adequate adaptation to the respective region of interest.

However, the difficulty lies in the fact that there is no adequate scientific methodology to evaluate a large number of genotypes in order to determine which ones carry alleles for a long juvenile period or to determine the exact juvenile period and inductive phase of each genotype of interest.

The present study aimed at describing an adequate methodology to identify and estimate the duration of the juvenile and the inductive periods in genotypes from different genetic origins, in soybean genetic breeding programs.

\section{MATERIAL AND METHODS}

The experiment was conducted at the Tropical Melhoramento e Genética (TMG) Research Center, located at latitude $23^{\circ} 16^{\prime}$ $\mathrm{S}$, longitude $51^{\circ} 17^{\prime} \mathrm{W}$ and $580 \mathrm{~m}$ of altitude, in Cambé, Paraná State, Brazil, during the autumn/winter of 2001 and 2002 under greenhouse conditions, with automatic temperature and lighting control. Eleven genotypes were selected for the study, which differ from the duration of the juvenile period (Table 1).

Table 1. Relationship of genotypes and their genealogies.

\begin{tabular}{ll}
\hline Genotypes & Genealogies \\
\hline Paraná & Hill x D52-810 (Hoanoke x Ogden) \\
Paranagoiana & Spontaneous mutation in Paraná \\
Bragg & Jackson x D49-2491 (S-100 x CNS) \\
BR 27 & (Bragg $^{3}$ x Santa Rosa) x (Bragg ${ }^{3}$ x IAC 73-2736-10*) \\
(Cariri) & D49-2491 $^{2}$ x Improved Pelican \\
Viçoja & Spontaneous mutation in Viçoja \\
UFV 1 & Collected in China by USDA \\
Biloxi & Viçoja x (Hill x PI 240664 \\
Doko & Collected in Peru by USDA \\
PI 159925 & FC 31919 (Collected in Venezuela by USDA) \\
Santa Maria & Hampton x (Hill x PI 240664) \\
Tropical & Ham
\end{tabular}

* mutation in cv. Hardee.

The experimental design included randomized blocks with split-plots, and the plots were represented by the variable number of days in which the genotypes remained under continuous light $(0,14,28,42$ and 56 days) and the sub-plots were represented by the genotypes under study. Nine genotypes were studied in 2001 (Paraná, Paranagoiana, Bragg, BR 27 (Cariri), Viçoja, UFV 1, Biloxi, Doko e PI 159925), with four replications per treatment. In 2002, 11 genotypes were investigated, the same in 2001, plus Santa Maria and Tropical, with three repetitions.

Ten L pots were used with substrate prepared with soil, compost organic and washed sand, in the respective proportions of $7: 2: 1 ; 0-20-20$ fertilizer formulation was added to the substrate at a dose of $8 \mathrm{~g}$ per pot. Artificial lighting was provided with 150 Watts Silvânia incandescent bulbs in order to eliminate any variation or susceptibility of plants to certain light wavelengths. So, during the day, the plants remained in the greenhouse under natural sunlight and, 17:00 every day, the lights were turned on and off automatically at 8:00 am the following day.

Under continuous light $(0,14,28,42$ and 56 days), ten seeds of each genotype were treated with a fungicide indicated for soybean crops and arranged in seedlings inside a growth chamber, at a constant temperature of $25^{\circ} \mathrm{C}$ for a period of 12 hours of light per day. Four days after the seeds are put to germination, the best seedlings were transplanted to pots (four seedlings per pot), and normal seedlings with the same radicle length were selected. Two weeks after transplantation, thinning was performed, leaving two plants per pot.

In both years, seeds from the first growing season were placed in a growth chamber on May 31 so that, on June 04, the seedlings were at an adequate stadium to be transplanted to a pot. After performing the transplantation, the lights were turned on at night, as mentioned before, so that the plants could remain continuously under light. On 14 June, seeds from the 2 nd season were placed in a germination chamber, and, on day 18, the seedlings were suitable for transplantation.

Thus, seeds were placed in a growth chamber every 14 days, and four days later they were suitable for transplantation. This procedure was replicated until the transplantation of the 5 th season, on July 30. On that date, plants had been 56, 42, 28, 14 and 0 days under continuous light, and supplementary lighting/ night was off to condition long nights and critical photoperiod to induce flowering. Thereafter, we computed the number of days until flowering with the opening of the first flower raceme in any plant. This procedure was performed for two years of study (2001 and 2002), strictly maintaining the same dates, to provide joint analyses and interpretations.

Generated data consisted of the independent variable age (variable $\mathrm{X}$ ), represented by the number of days under continuous light at five levels $(0,14,28,42$, and 56 days), which influenced the number of days to early flowering $(\mathrm{Y})$ of each genotype. Analyses of individual (per year) and joint variances were performed, in addition to mean tests for the characteristic number of days to flowering. The juvenile period estimate was obtained by a point of contrast between the maximum and the minimum point of the number of days to flowering regression function $(\mathrm{Y})$ and the number of days under continuous light $(\mathrm{X})$, in the observed range of 0-56 days (Figure 1). The regression model adopted for all genotypes was not linear, of the decreasing exponential type, whose function is:

$$
y=(a-b) \exp (-c x)+b
$$

where the parameter "a" indicates the value of $y$ when $x=0$, the " $b$ " indicates the point of the absolute minimum of the function and "c" is a component of the decrease rate equation, which interferes in the concavity of the curve, where the closer to zero, the "straighter" is the "curve".

The inductive phase was estimated by the number of days that took 56-day old plants under continuous light exposure to flower. The juvenile period was estimated by the difference between the number of days to flowering of plants without supplemental light and the number of days to flowering of plants with 56 days of supplementary light. Therefore, the juvenile period is the number of days that zero-day 24-hour light / day plants lead to flower, subtracting their respective inductive period. The sum of these two phases (juvenile period and inductive) comprises the vegetative stage of the plants or the number of days to flowering.

\section{RESULTS AND DISCUSSION}

Analyses of variance for the days to flowering individual variable, with the split-plot model presented in Table 2, indicated significant effect on plant age (number of days under continuous light), replications, genotypes and genotypes $\mathrm{x}$ age interactions. Number of days to flowering means was 32 and 33 days for the 
Table 2. Analysis of individual variance for number of days to flowering.

\begin{tabular}{|c|c|c|c|c|}
\hline \multirow{2}{*}{$\begin{array}{l}\text { Source of } \\
\text { Variation }\end{array}$} & \multicolumn{2}{|c|}{2001 year } & \multicolumn{2}{|r|}{2002 year } \\
\hline & DF & Mean Square & $\mathrm{DF}$ & Mean Square \\
\hline Period (P) & 4 & $2488.67^{* *}$ & 4 & $1385.38^{* * *}$ \\
\hline Repetitions & 3 & $11.86^{*}$ & 2 & $6.14^{*}$ \\
\hline Error (a) & 12 & 2.06 & 8 & 7.27 \\
\hline Genotypes & 8 & $605.51^{* *}$ & 10 & $538.94^{* * *}$ \\
\hline$P \times G$ & 32 & $179.10^{* *}$ & 40 & $70.13^{* *}$ \\
\hline Error (b) & 120 & 1.18 & 100 & 1.57 \\
\hline Total & 179 & & 164 & \\
\hline Mean & & 32.29 & & 33.10 \\
\hline Coef. Variation & & 3.36 & & 3.78 \\
\hline
\end{tabular}

*** Significant at $5 \%$ and $1 \%$ probability by $\mathrm{F}$ test, respectively.
Table 3. Analysis of joint variance for number of days to flowering.

\begin{tabular}{|c|c|c|c|}
\hline Source of variation & $\mathrm{DF}$ & Mean Square & \\
\hline Years $(Y)$ & 1 & $26.62^{\text {ns }}$ & \\
\hline Period (P) & 4 & $3827.71^{* *}$ & \\
\hline $\mathrm{Y} \times \mathrm{P}$ & 4 & $105.43^{* *}$ & \\
\hline Repetitions/year & 5 & $9.57^{\mathrm{ns}}$ & \\
\hline P x Repetitions/year & 20 & $4.14^{* *}$ & \\
\hline Genotypes (G) & 10 & $993.15^{* *}$ & \\
\hline$Y \times G$ & 8 & $8.86^{* * *}$ & \\
\hline$P \times G$ & 40 & $194.30^{* *}$ & \\
\hline$Y \times P x G$ & 32 & $9.07^{* *}$ & \\
\hline Error & 220 & & \\
\hline Total & 344 & & \\
\hline Mean & & & 32.68 \\
\hline Coef. Variation (\%) & & & 3.56 \\
\hline
\end{tabular}

**** Significant at $5 \%$ and $1 \%$ probability by $\mathrm{F}$ test, respectively.

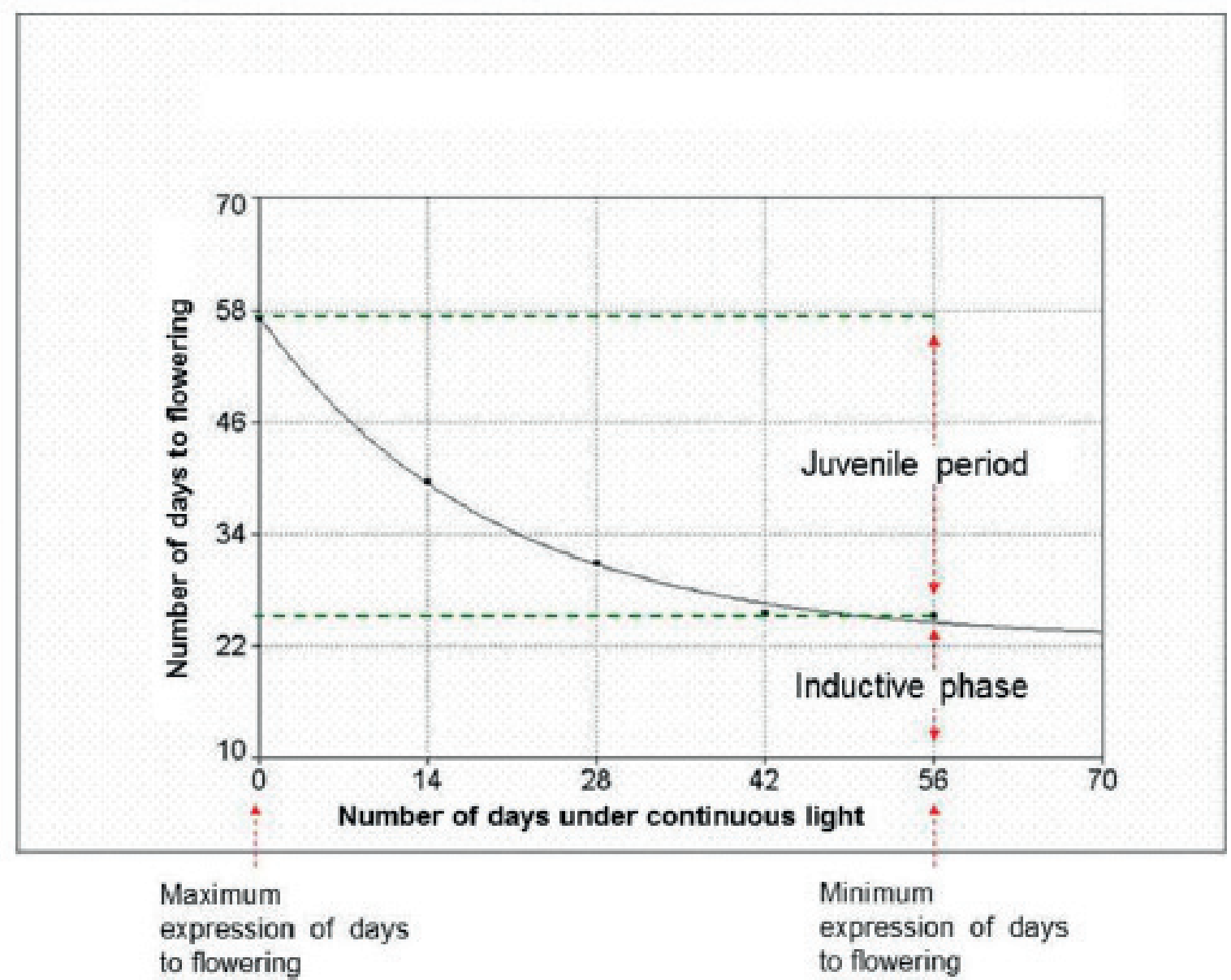

Figure 1. Representation of the estimates of the inductive phase and the juvenile period, based on the regression of the number of days to flowering $(\mathrm{Y})$, depending on the number of days under continuous light $(\mathrm{X})$, for a hypothetical genotype soybean. 


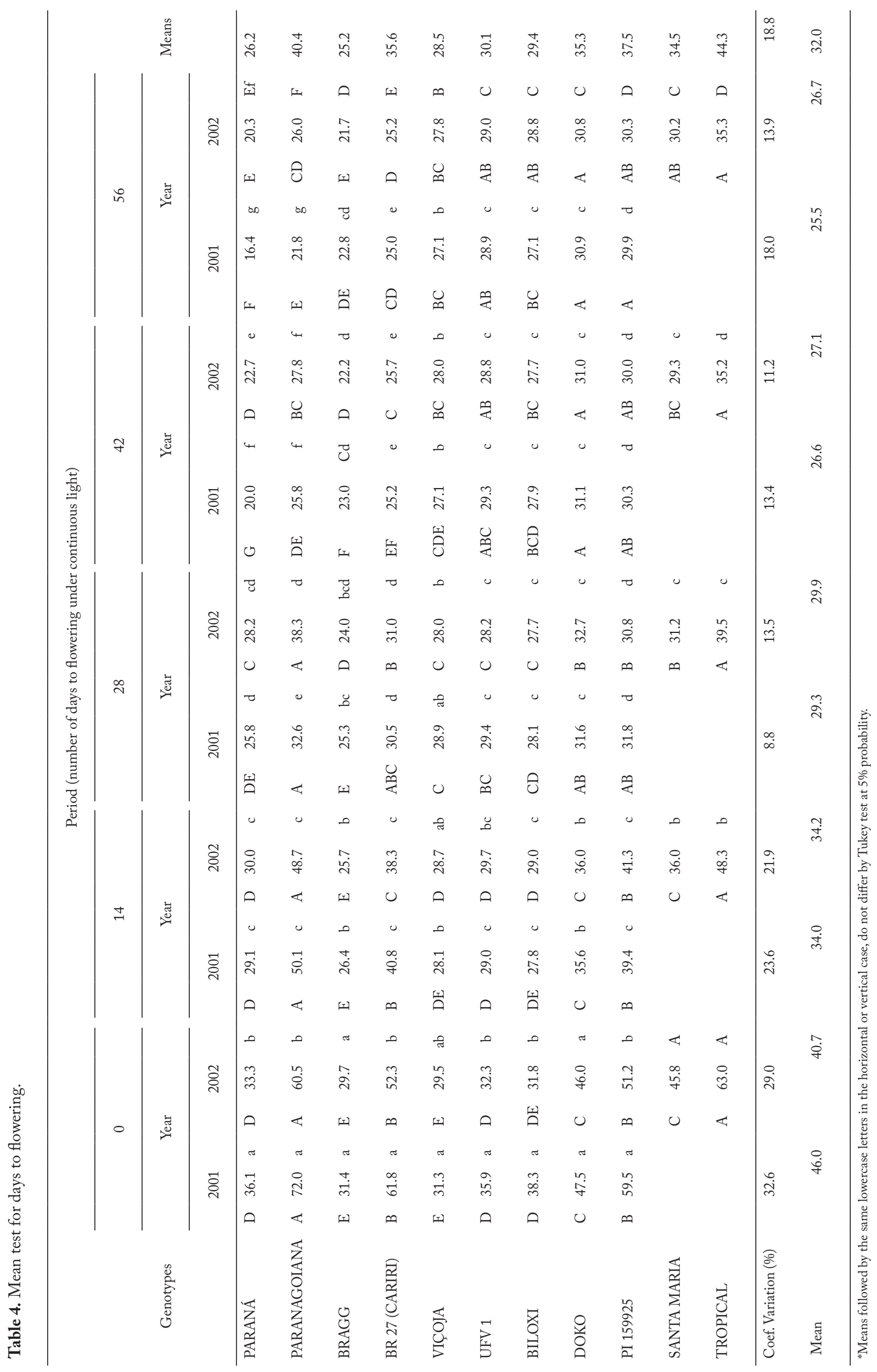



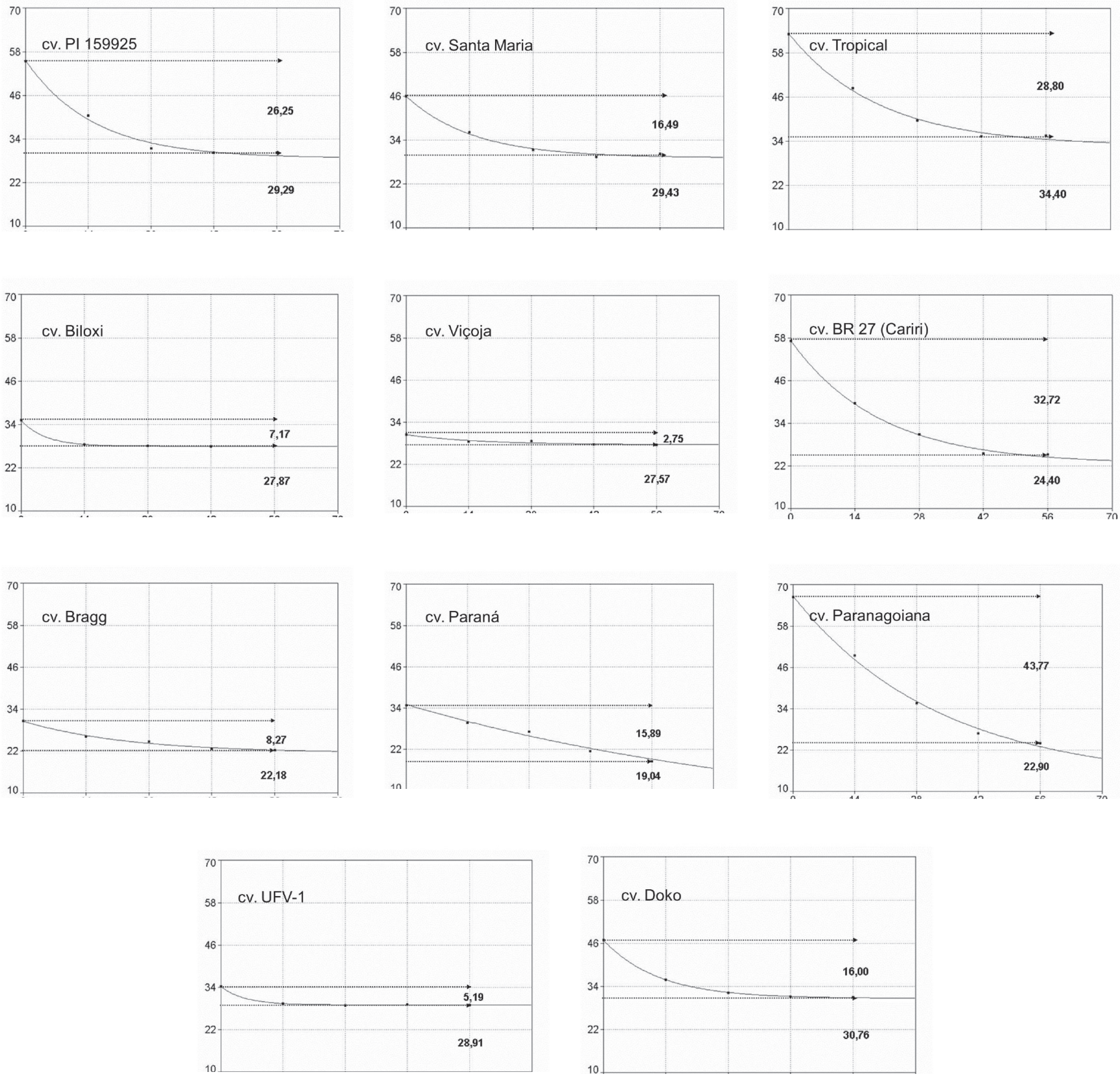

Figure 2. Regression of the number of days to flowering ( $\mathrm{y}$-axis) depending on the plants' age ( $\mathrm{x}$-axis), under continuous light for the 11 soybean genotypes.

years 2001 and 2002, respectively, with a coefficient of variation of $3.36 \%$ for 2001 and $3.78 \%$ for 2002 . The joint variance analysis revealed significance for all simple effects and their interactions, with the exception of the year factor and replications within year (Table 3). Due to the significance of the interactions, they were split based on the means tests (Table 4).

The result presented by the means test (Table 4) showed no significant difference between years within the same age for most genotypes (horizontal comparison between columns). Noteworthy is the Viçoja genotype which differed from the others only in the zero age.

The vertical comparison showed that there was a significant effect of genotypes for all periods and years, being the Paranagoiana, with late flowering under all conditions, along with the Tropical genotype for the 0,14 and 28 days under continuous light. At the other extreme, the Bragg genotype was the earliest, except for the period of 42 days in 2001.

To better understand these results, a regression analysis of days to flowering was performed, according to the period of the plants under continuous light (Figure 1). A comparison between the Paraná and the Paranagoiana cultivars showed that the latter has clear superiority regarding days to flowering in all period. Paraná showed negative linear response, with no indication of reaching a state of balance, parallel to the $\mathrm{x}$ axis. The superiority of Paranagoiana regarding number of days to flowering in relation to its ancestral genotype Paraná is conditioned by its largest juvenile period, the result of a genic mutation controlled by a recessive allele, as studied by Bonato and Vello (1999).

The Bragg and BR 27 (Cariri) cultivars showed the effective gains in late flowering occurred with BR 27 (Cariri), although it was originated by Bragg by backcrossing, and the Bragg showed classical behavior in relation to photoperiod. The result attested the effectiveness of the objective set by Dr. Romeu Kiihl to obtain a cultivar adapted to low-latitude regions, in this case, the BR 27 (Cariri), with the Bragg agronomic type, but with good development under these agro-ecological conditions. 
The Viçoja and its spontaneous mutant UFV-1 (Figure 2) showed similar performance and the absence of a long juvenile period, differing only in number of days to flowering, at age 0 . These results confirm that the UFV-1 mutant is used only for late cycles in relation to Viçoja and non- mutant for a long juvenile period.

The Biloxi is highly studied material, being a typical example of sensitivity to photoperiod in soybean (Collinson et al. 1993). It has been found that their behavior is of the classical type, that is, with almost no juvenile period, according to the findings of Garner and Allard (1920).

In Figure 1, the cultivar Doko shows an intermediate flowering curve, much similar to that of 'Santa Maria. The Santa Maria was used in studies of Kiihl (1976) and Hartwig and Kiihl (1979) as a source of alleles for long juvenile periods. Doko was a mutant identified by Dr. Romeu Kiihl and it was used as a parental to obtain several cultivars adapted to Brazilian tropical regions of lower latitudes (Neumaier and James 1993).

The PI 159925 and Tropical genotypes presented parallel performance, with the Tropical cultivar always higher in plants of all ages, under continuous light. The Tropical, a descendant of PI 240664, adapted to low latitudes, and one of the first successful cultivars for the Brazilian tropical region (Neumaier and James 1993), has a long juvenile period compared to PI 159925 which also carries a long juvenile period and was used as a source of alleles in early studies developed in Brazil, being also explored quite a long time to understand the legacy of the long juvenile period (Miyasaka et al. 1970; Kiihl and Garcia 1989; Sinclair and Hinson 1992, Ray et al. 1995).

Table 5 shows the regression equations coefficients for the decreasing exponential model for all genotypes. It appears that this model was adjusted for all genotypes, except Viçoja with determination coefficient around 0.77 and not significant for the $\mathrm{F}$ model (significance obtained 5.70\%).

In Table 6, the estimated number corresponding to the in-

Table 5. Regression coefficients ( $a, b$ and $c$ ), determining original coefficient (R2) and adjusted by the degrees of freedom equation (R2 aj.), F-test of the regression and significance for the variable number of days to flowering in function of the number of days under continuous light for 11 soybean genotypes.

\begin{tabular}{|c|c|c|c|c|c|c|c|}
\hline \multirow{2}{*}{ Genotypes } & \multicolumn{7}{|c|}{ Regression parameters } \\
\hline & A & $\mathbf{b}$ & c & $\mathrm{R} 2$ & R2 aj. & $\mathbf{F}$ & Sig \\
\hline Paraná & 34.93 & 0.00 & 0.01 & 0.984 & 0.935 & 60.48 & $*$ \\
\hline Paranagoiana & 66.66 & 13.08 & 0.03 & 0.996 & 0.985 & 262.50 & *** \\
\hline Bragg & 30.45 & 21.35 & 0.04 & 0.990 & 0.958 & 95.21 & $*$ \\
\hline $\begin{array}{l}\text { BR } 27 \\
\text { (Cariri) }\end{array}$ & 57.12 & 22.49 & 0.05 & 0.998 & 0.991 & 463.79 & $* *$ \\
\hline Viçoja & 30.32 & 27.48 & 0.06 & 0.943 & 0.770 & 16.41 & ns \\
\hline UFV 1 & 34.11 & 28.91 & 0.18 & 0.998 & 0.991 & 443.53 & *** \\
\hline Biloxi & 35.04 & 27.87 & 0.19 & 0.999 & 0.998 & 1782.97 & *** \\
\hline Doko & 46.76 & 30.59 & 0.08 & 1.000 & 0.999 & 7349.06 & $* *$ \\
\hline PI 159925 & 55.53 & 28.63 & 0.07 & 0.991 & 0.964 & 109.16 & $* *$ \\
\hline Santa Maria & 45.92 & 29.06 & 0.07 & 0.993 & 0.971 & 134.75 & $* *$ \\
\hline Tropical & 63.19 & 32.65 & 0.05 & 0.995 & 0.980 & 196.99 & *** \\
\hline C.V. $(\%)$ & & & & & 1.6 & 6.8 & \\
\hline Means & & & & & 0.990 & 0.958 & \\
\hline
\end{tabular}

\footnotetext{
*** Significant at $5 \%$ and $1 \%$ probability by $\mathrm{F}$ test, respectively.
}

Table 6. Estimation of the inductive phase (IP) and the juvenile period (JP), according to the parameters of the decreasing exponential regression equation for the variable number of days to flowering, in the number of days under continuous light, for 11 soybean genotypes.

\begin{tabular}{|c|c|c|c|c|c|}
\hline \multirow{6}{*}{ Genotypes } & \multicolumn{3}{|c|}{ Parameters } & \multicolumn{2}{|c|}{ Vegetative phase } \\
\hline & (1) & (2) & (3) & (4) & (5) \\
\hline & Maximum & Partial & Absolute & Inductive & Juvenile \\
\hline & Point & Minimum & Minimum & Phase & Period \\
\hline & (a) & Point & Point & (2) & $(1-2)$ \\
\hline & $(\mathrm{x}=0)$ & $(x=56)$ & (b) & IP & $\mathrm{JP}$ \\
\hline Paraná & 34.93 & 19.04 & 0.00 & 19.04 & 15.89 \\
\hline Paranagoiana & 66.66 & 22.90 & 13.08 & 22.90 & 43.77 \\
\hline Bragg & 30.45 & 22.18 & 21.35 & 22.18 & 8.27 \\
\hline $\begin{array}{l}\text { BR } 27 \\
\text { (Cariri) }\end{array}$ & 57.12 & 24.40 & 22.49 & 24.40 & 32.72 \\
\hline Viçoja & 30.32 & 27.57 & 27.48 & 27.57 & 2.75 \\
\hline UFV 1 & 34.11 & 28.91 & 28.91 & 28.91 & 5.19 \\
\hline Biloxi & 35.04 & 27.87 & 27.87 & 27.87 & 7.17 \\
\hline Doko & 46.76 & 30.76 & 30.59 & 30.76 & 16.00 \\
\hline PI 159925 & 55.53 & 29.29 & 28.63 & 29.29 & 26.25 \\
\hline Santa Maria & 45.92 & 29.43 & 29.06 & 29.43 & 16.49 \\
\hline Tropical & 63.19 & 34.40 & 32.65 & 34.40 & 28.80 \\
\hline C.V. $(\%)$ & 29.6 & 16.4 & 40.3 & 16.4 & 70.2 \\
\hline Means & 45.46 & 26.98 & 23.83 & 26.98 & 18.48 \\
\hline
\end{tabular}

ductive phase and the juvenile period days are presented. The inductive phase is estimated by the partial minimum point of the regression equation, in which $\mathrm{x}=56$ days is the largest $\mathrm{x}$ value observed in this decreasing function. The juvenile period was obtained by subtracting the maximum point of the partial equation, which is achieved when the value of $\mathrm{x}$ (days under continuous light) is equal to zero, and by subtracting the minimum point part when $\mathrm{x}=56$ days, i.e., column 1 minus column 2 in the referred table.

We observed average values for the partial maximum point for days to flowering of about 45 days, 27 days for the inductive phase; and, consequently, 18 days for the average juvenile period, among the 11 genotypes (Table 6). It is suggested to compare the partial minimum point with the absolute minimum point of the function estimated by the coefficient " $b$ " of the exponential decay equation. The closer the values, the greater the model adjustment security is. It appears that the Paraná genotype showed distinct behavior from other genotypes, an almost linear declining behavior with absolute minimum point at zero value. The second lowest point of absolute minimum was obtained by genotype Paranagoiana, a direct mutant from the Paraná genotype.

Estimates of the number of days to flowering, inductive phase and juvenile period by replications were performed by joint analysis, generating a means comparison test between genotypes, as shown in Table 7, where significant differences among the means of the genotypes for all variables are found. Paranagoiana and Tropical have late flowering, with more than 60 days, but differ significantly in regards to the inductive phase and juvenile period. According to the juvenile period means test, the Paranagoiana genotype presented the highest value (first group); followed by the second group, the BR 27 (Cariri); the third group, PI 159925 and Tropical; the fourth group, Paraná, Santa Maria and Doko; the fifth UFV-1, Biloxi and Bragg; and the last group, the one with lower values for the juvenile period, Viçoja, together with its direct mutant UFV-1. 
Table 7. Mean test for days to flowering, inductive phase and juvenile period for 11 soybean genotypes.

\begin{tabular}{lclllll}
\hline \multicolumn{1}{c}{ Genotypes } & \multicolumn{3}{c}{$\begin{array}{c}\text { Days to } \\
\text { flowering }\end{array}$} & \multicolumn{2}{c}{$\begin{array}{c}\text { Inductive phase } \\
\text { (days) }\end{array}$} & $\begin{array}{c}\text { Juvenile period } \\
\text { (days) }\end{array}$ \\
\hline Paraná & 34.93 & $\mathrm{D}$ & 19.04 & $\mathrm{E}$ & 15.89 & $\mathrm{D}$ \\
Paranagoiana & 66.67 & $\mathrm{~A}$ & 22.90 & $\mathrm{CD}$ & 43.77 & $\mathrm{~A}$ \\
Bragg & 30.45 & $\mathrm{E}$ & 22.18 & $\mathrm{D}$ & 8.27 & $\mathrm{E}$ \\
BR 27 (Cariri) & 57.12 & $\mathrm{~B}$ & 24.40 & $\mathrm{C}$ & 32.72 & $\mathrm{~B}$ \\
Viçoja & 30.32 & $\mathrm{E}$ & 27.57 & $\mathrm{BC}$ & 2.75 & $\mathrm{~F}$ \\
UFV 1 & 34.10 & $\mathrm{D}$ & 28.91 & $\mathrm{~B}$ & 5.19 & $\mathrm{EF}$ \\
Biloxi & 35.04 & $\mathrm{D}$ & 27.87 & $\mathrm{~B}$ & 7.17 & $\mathrm{E}$ \\
Doko & 46.76 & $\mathrm{C}$ & 30.76 & $\mathrm{~B}$ & 16.00 & $\mathrm{D}$ \\
PI 159925 & 55.54 & $\mathrm{~B}$ & 29.29 & $\mathrm{~B}$ & 26.25 & $\mathrm{C}$ \\
Santa Maria & 45.92 & $\mathrm{C}$ & 29.43 & $\mathrm{~B}$ & 16.49 & $\mathrm{D}$ \\
Tropical & 63.20 & $\mathrm{~A}$ & 34.40 & $\mathrm{~A}$ & 28.80 & $\mathrm{C}$ \\
\hline C.V. (\%) & 29.57 & & 16.36 & & 70.19 & \\
Mean & 45.46 & & 26.98 & & 18.48 & \\
\hline
\end{tabular}

*Means followed by the same letter vertically are not statistically different by Tukey test at $5 \%$ probability.

\section{REFERENCES}

Bonato, E. R. and Vello, N. A. (1999) Aspectos genéticos do tempo para o florescimento em variantes naturais de soja. Pesquisa Agropecuária Brasileira, Brasília, 34 (6): 989-993.

Cober, E.R. (2011) Long Juvenile Soybean Flowering Responses under Very Short Photoperiods. Crop Science 51: 140-145.

Cober, E.R., Molnar, S.J., Charette, M. and Voldeng, H.D. (2010) A New Locus for Early Maturity in Soybean. Crop Science 50: 524-527.

Cober, E.R. and Voldeng, H.D. (2001) A New Soybean Maturity and Photoperiod-Sensitivity Locus Linked to $E 1$ and T. Crop Science 41: 698-701.

Cober, E.R. and Voldeng, H.D. (2001) Low R: FR Light Quality Delays Flowering of E7E7 Soybean Lines. Crop Science 41: 1823-1826.

Collinson, S.T., Summerfield, R.J., Ellis, R.H. and Roberts, E.H. et al. (1993) Durations of the photoperiod-sensitive and photoperiod-insensitive phases of development to flowering in four cultivars of soybean (Glycine max (L.) Merrill). An. Bot. 71: 389394.

Destro, D., Faria, A.P., Destro, T.M., Faria, R.T., Gonçalves, L.S.A. and Lima, W.F. (2013) Food type soybean cooking time: a review. Crop Breeding and Applied Biotechnology 13(3): 194199.

Destro, D., Pípolo, V.C., Kiihl, R.A.S. and Almeida, L.A.A. (2001) Photoperiodism and Genetic Control of the Long Juvenile Period in Soybean: a review. Crop Breeding and Applied Biotechnology 1(1): 72-92.

Garner, W.W. and Allard, H.A. (1920) Effect of relative lenght of day and night and other factors of the environment on growth and reproduction in plants. Journal of Agricultural Research 18: 553-606.

Hartwig, E.E. and Kiihl, R.A.S. (1979) Identification and utilization of delayed flowering character in soybeans for short-day conditions. Field Crops Research 2: 145-151.

Hichs, D.R. (1978) Growth and Development. In. Norman, A.G.
(Ed.). Soybean: physiology, agronomy and utilization. Academic Press, New York, pp. 17-44.

Kiihl, R.A.S. and Almeida, L.A. (2001) Melhoramento da Soja para as Médias e Baixas latitudes. In. Anais I Congresso Brasileiro de Melhoramento de Plantas, 2001, Goiânia, GO. Embrapa/ Agencia Goiana de Desenvolvimento Rural e Fundiário, Goiana.

Kiihl, R.A.S. (1976) Inheritance studies of two characters in soybean (Glycine max (L.) Merrill); I. Resistance to soybean mosaic virus; II. late flowering under short-day conditions. 65p. Thesis (PhD) - Mississippi State University.

Kiihl, R.A.S. and Garcia, A. (1989) The use of the long-juvenile trait in breeding soybean cultivars, In: IV Proceedings World Soybean Research Conference, 1989, Buenos Aires. Asociacion Argentina de la soja, Buenos Aires. pp. 994-1000.

Miyasaka, S., Guimarães, G. and Kiihl, R.A.S. et al. (1970) Variedades de soja indiferentes ao fotoperiodismo e tolerantes a baixas temperaturas. Bragantia 29: 169-174.

Neumaier, N. and James, AT. (1993) Exploiting the long Juvenile trait to improve adaptation of soybeans to the tropics. Food Legume Newsletter 18: 12-14.

Ray, J.D., Hinson, K. and Mankono, E.B. et al. (1995) Genetic Control of a long-juvenile trait in soybean. Crop Science 35: 1001-1006.

Sinclair, T .R. and Hinson, K. (1992) Soybean flowering in response to the juvenile trait. Crop Science 32: 1242-1248.

Sinclair, T.R., Neumaier, N., Farias, J.R.B. and Nepomuceno, A.L. (2005) Comparison of vegetative development in soybean cultivars for low-latitude environments. Field Crops Research 92: 53-59.

Received: January 13, 2015.

Accepted: February 09, 2015.

Published: April 02, 2015. 